\title{
Comparison between Phase-Shift Full-Bridge Converters with Noncoupled and Coupled Current-Doubler Rectifier
}

\author{
Cheng-Tao Tsai, ${ }^{1}$ Jye-Chau Su, ${ }^{2}$ and Sheng-Yu Tseng ${ }^{3}$ \\ ${ }^{1}$ Department of Electrical Engineering, National Chin-Yi University of Technology, Taichung 41170, Taiwan \\ ${ }^{2}$ Department of Electronic Engineering, National Chin-Yi University of Technology, Taichung 41170, Taiwan \\ ${ }^{3}$ Department of Electrical Engineering, Chang-Gung University, Tao-Yuan 33344, Taiwan \\ Correspondence should be addressed to Jye-Chau Su; jc07@ms34.hinet.net
}

Received 31 July 2013; Accepted 20 October 2013

Academic Editors: G. De Mey, S. A. Mahmoud, and G. Priebe

Copyright (C) 2013 Cheng-Tao Tsai et al. This is an open access article distributed under the Creative Commons Attribution License, which permits unrestricted use, distribution, and reproduction in any medium, provided the original work is properly cited.

\begin{abstract}
This paper presents comparison between phase-shift full-bridge converters with noncoupled and coupled current-doubler rectifier. In high current capability and high step-down voltage conversion, a phase-shift full-bridge converter with a conventional currentdoubler rectifier has the common limitations of extremely low duty ratio and high component stresses. To overcome these limitations, a phase-shift full-bridge converter with a noncoupled current-doubler rectifier (NCDR) or a coupled current-doubler rectifier (CCDR) is, respectively, proposed and implemented. In this study, performance analysis and efficiency obtained from a $500 \mathrm{~W}$ phase-shift full-bridge converter with two improved current-doubler rectifiers are presented and compared. From their prototypes, experimental results have verified that the phase-shift full-bridge converter with NCDR has optimal duty ratio, lower component stresses, and output current ripple. In component count and efficiency comparison, CCDR has fewer components and higher efficiency at full load condition. For small size and high efficiency requirements, CCDR is relatively suitable for high stepdown voltage and high efficiency applications.
\end{abstract}

\section{Introduction}

In a decentralized power system, the front end ac/dc converter is generally composed of two stages, in which one is a power factor correction (PFC) and the other is an intermediate $\mathrm{dc} / \mathrm{dc}$ converter, as shown in Figure 1. Most of PFC circuits adopt a boost converter [1], and an intermediate converter is usually with an isolated version [2]. Using a boost converter can achieve a unity power factory, and using an isolated converter can provide galvanic isolation and high output current. In off-line applications, universal ac voltage is always into dc $400 \mathrm{~V}$ as a dc bus by boost converters, and an intermediate $\mathrm{dc} / \mathrm{dc}$ converter converts it to a low voltage bus of $24 \mathrm{~V}_{\mathrm{dc}}$ or $12 \mathrm{~V}_{\mathrm{dc}}$. Therefore, for high output current and low output voltage applications, an isolated dc/dc converter is usually required.

To achieve low output voltage, high output current, and high efficiency, a phase-shift full-bridge converter with conventional current-doubler rectifier is widely used in mediumhigh power condition, as shown in Figure 2 [3]. Nevertheless, it still has several limitations. For example, for high stepdown voltage conversion, it requires a transformer with high turns ratio or it has to reduce the duty ratio of the switches. A high turns ratio will result in high duty loss and low conversion efficiency, while a low duty ratio will increase input peak current and component stress [4]. The other limitation is that its large external resonant inductor will induce a large circulation current, which will flow through the primary winding of the transformer and the switches during a freewheeling interval. As a result, conduction loss in the switches and copper loss in the transformer are significant. To release the above-mentioned limitations of the conventional full-bridge converter with current-doubler, many approaches have been conducted [3-7]. However, their high step-down voltage ratio still result in extremely low duty ratio, which will induce high peak current through the secondary winding of the isolation transformer and output filter inductors, increasing copper loss and component stresses [8-12].

To solve the above-mentioned problem, the phase-shift full-bridge converter with NCDR or CCDR is proposed, 


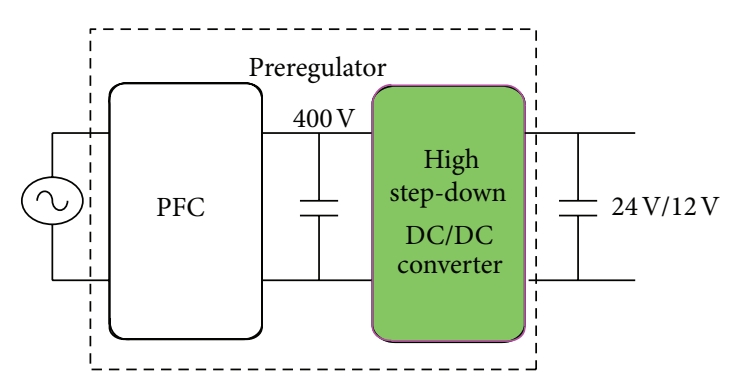

FIGURE 1: Two-stage structure of preregulator.

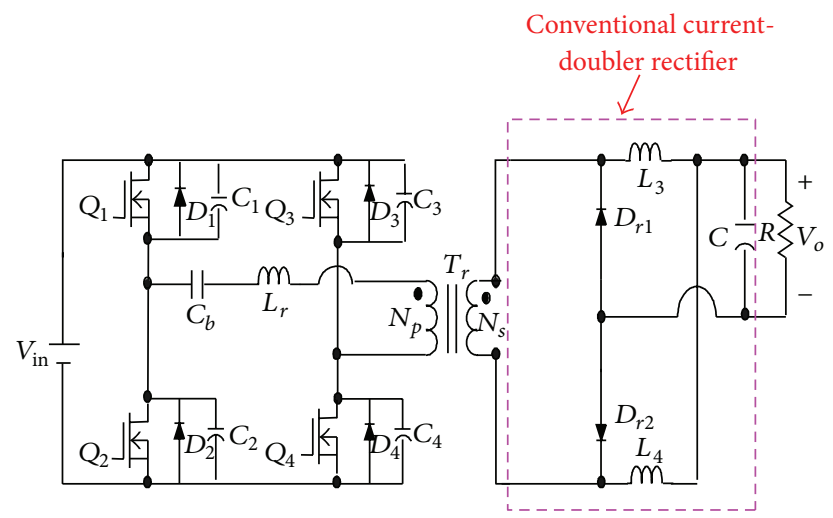

FIGURE 2: The phase-shift full-bridge converter with conventional current-doubler rectifier.

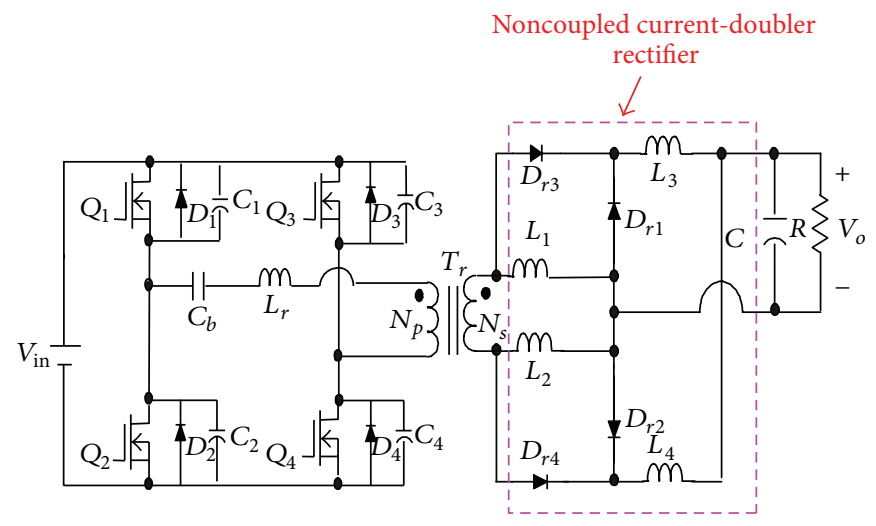

FIGURE 3: The proposed phase-shift full-bridge converter with NCDR.

as shown in Figures 3 and 4 [13]. They can alleviate the drawbacks of extremely low duty ratio and high component stresses. The two proposed improved rectifiers can extend duty ratio of the active switches to reduce the peak current through the secondary winding of the transformer and lower output current ripple. The conversion efficiency can be increased significantly. Section 2 describes derivation and operational principle of the two proposed improved currentdoubler rectifiers. Section 3 compares the benefits of the two improved current-doubler rectifiers. Power loss and efficiency estimation are described in Section 4. Experimental results obtained from a $500 \mathrm{~W}$ phase-shift full-bridge converter with NCDR and CCDR are presented in Section 5. Finally, a conclusion is given in Section 6.

\section{Derivation of Improved Current-Doubler Rectifiers}

With duality method, NCDR can be derived from a voltagequadrupler circuit, and coupled-doubler can be derived from a voltage-doubler circuits. In the following, derivations of both improved current-doubler rectifiers are described in details.

2.1. Derivation of NCDR. Derivation of NCDR is based on a conventional voltage-quadrupler circuit, as shown in Figure 5(a). According to duality principle, meshes of the voltage quadrupler are replaced with nodes, and capacitors 


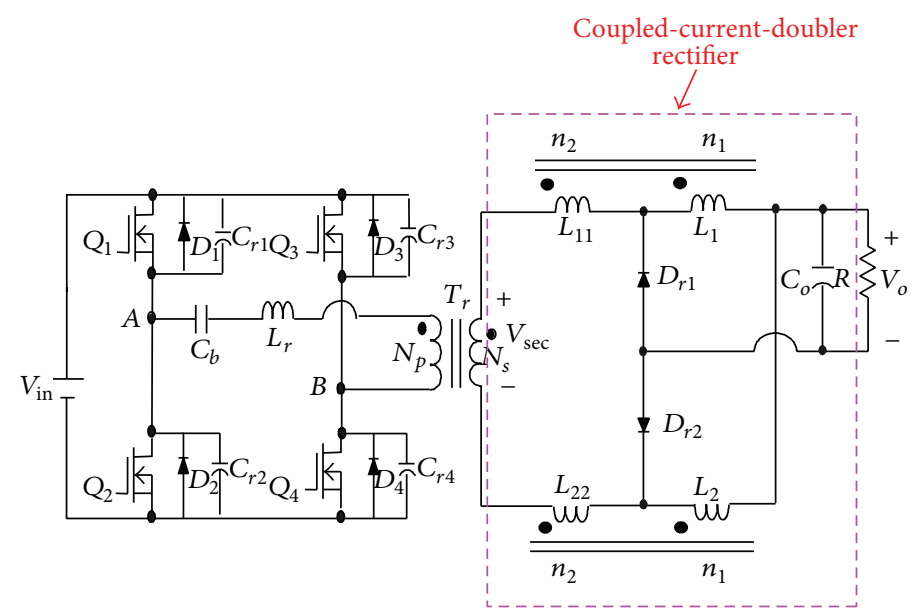

FIGURE 4: The proposed phase-shift full-bridge converter with CCDR.

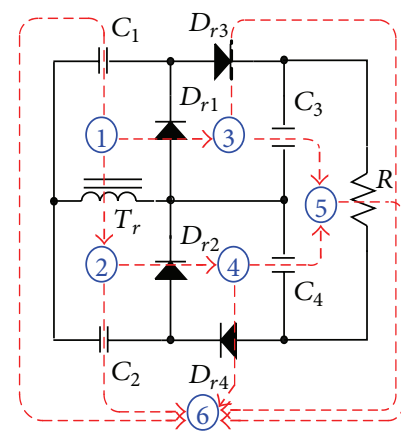

(a)

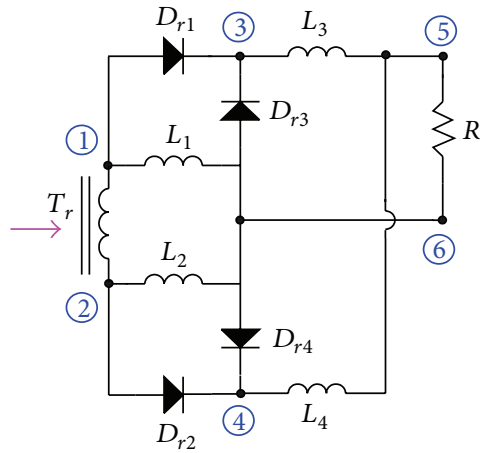

(b)

FIGURE 5: Derivation of NCDR from a voltage-quadrupler based on duality principle: (a) voltage-quadrupler and (b) NCDR.

are replaced with inductors, while diodes are with no change, yielding the proposed NCDR as shown in Figure 5(b).

2.2. Derivation of CCDR. Similarly, derivation of CCDR is based on a conventional voltage-doubler circuit, as shown in Figure 6(a). According to duality principle, meshes of the voltage doubler are replaced with nodes, and capacitors are replaced with inductors, while diodes are with no change, yielding the conventional current-doubler rectifier as shown in Figure 6(b). Utilizing coupled inductor concept, the output filter inductors can be extended to the coupled ones, as shown in Figure 6(c).

\section{Operational Principles of NCDR and CCDR}

For NCDR and CCDR, each of which has its own merits and demerits. To have an objective judgment, operational principles of NCDR and CCDR are briefly described as follows.

3.1. Operational Principle of NCDR. In Figure 3, the proposed phase-shift full-bridge converter with NCDR under continuous inductor current operation can be divided into four major operating modes over a half switching cycle. Figure 7 shows conceptual voltage and current waveforms relative to key components of NCDR. $D_{\text {eff }}$ and $D_{\text {loss }}$ are denoted as the effective and loss duty ratios, respectively. $V_{A B}$ is the voltage across the resonant inductor $L_{r}$ and the isolation-transformer primary winding, $V_{\mathrm{sec}}$ is the voltage across the isolationtransformer secondary winding, $i_{\mathrm{sec}}$ is the secondary current, $i_{L_{1}}$ and $i_{L_{2}}$ are the current of the energy inductors, $i_{L_{3}}$ and $i_{L_{4}}$ are the current of the output filter inductors, and $i_{D_{1}} \sim i_{D_{4}}$ are the current of the rectifier diodes. To simplify description of the steady-state operational modes, the phase-shift fullbridge converter will not be discussed in this section. Only the proposed NCDR is analyzed. Under continuous inductor current operation, four major operating modes of the NCDR are identified over a half switching cycle. Figure 8 shows equivalent circuits of the NCDR operational modes.

Mode 1 (Figure 8(a), $t_{0} \leq t<t_{1}$ ). At time $t_{0}$, a positive voltage $V_{\text {sec }}$ crosses the secondary winding of transformer $T_{r}$. First of all, diode $D_{r 3}$ is reversely biased and $D_{r 1}, D_{r 2}$, and $D_{r 4}$ are conducting. During this interval, inductor current $i_{L_{3}}$ flowing through the path $V_{o}-L_{2}-V_{\mathrm{sec}}-D_{r 1}-L_{3}$ is linearly increased, and inductor currents $i_{L_{1}}$ and $i_{L_{4}}$ are linearly decreased.

Mode 2 (Figure 8(b), $t_{1} \leq t<t_{2}$ ). At time $t_{1}$, the secondary current $i_{\text {sec }}$ is equal to inductor current $i_{L_{3}}$, and diode $D_{r 2}$ is 


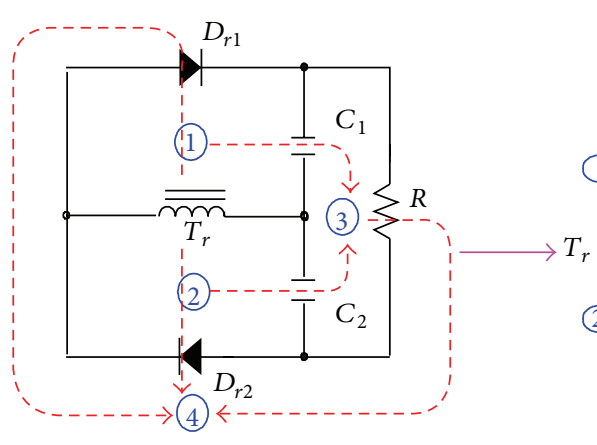

(a)

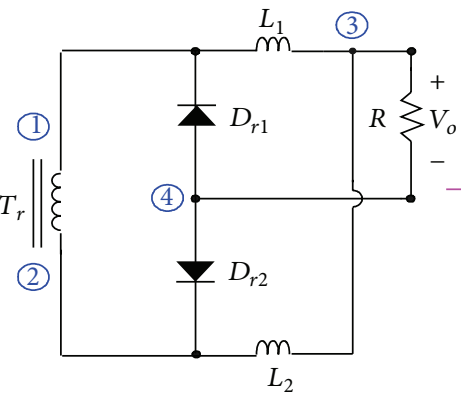

(b)

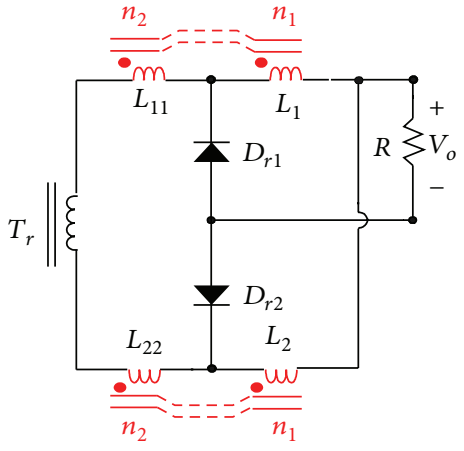

(c)

FIGURE 6: Derivation of CCDR from a voltage-doubler based on duality principle: (a) voltage-doubler, (b) conventional current-doubler rectifier, and (c) CCDR.

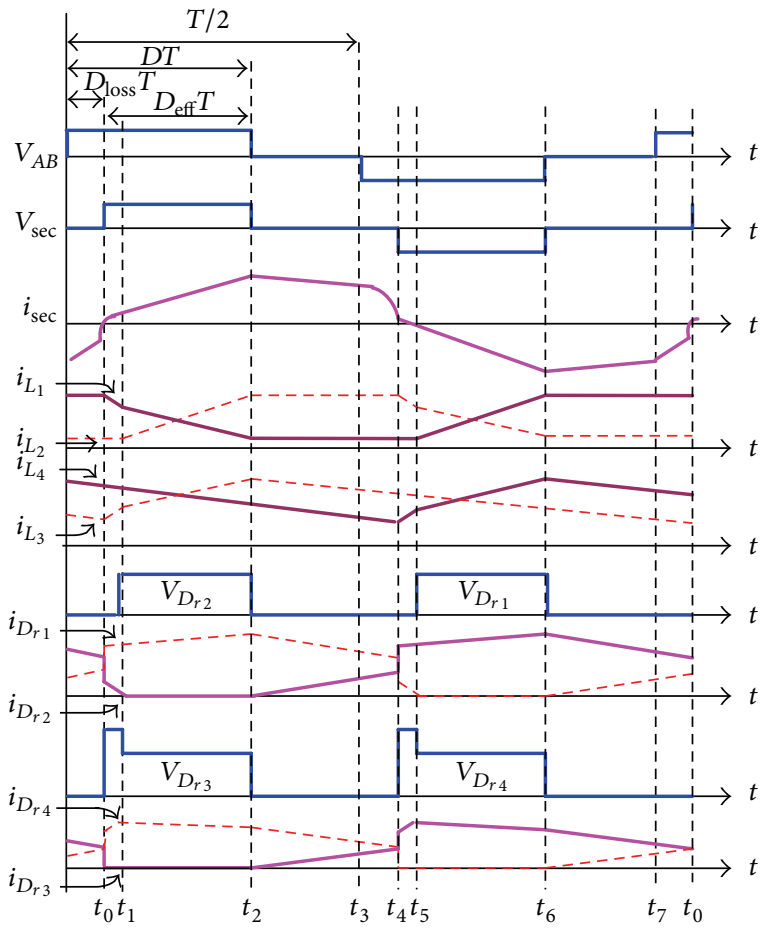

FIGURE 7: Key waveforms of the proposed phase-shift full-bridge converter with NCDR.

reversely biased. Inductor current $i_{L_{2}}=i_{L_{3}}$ flowing through the path $V_{\text {sec }}-D_{r 1}-L_{3}-V_{o}-L_{2}$ is linearly increased, while the energy stored in inductor $L_{1}$ and $L_{4}$ will be released through the rectifier diode $D_{r 1}$ and $D_{r 4}$ to the load, respectively.

Mode 3 (Figure 8(c), $t_{2} \leq t<t_{3}$ ). When voltage $V_{\text {sec }}$ drops to zero at time $t_{2}$, all of the diodes $\left(D_{r 1} \sim D_{r 4}\right)$ are conducting. During this interval, the inductor current $i_{L_{3}}$ flowing through two paths $V_{o}-D_{r 3}-L_{3}$ and $V_{o}-L_{2}-V_{\text {sec }}-D_{r 1}-L_{3}$ and the inductor current $i_{L_{4}}$ flowing through $V_{o}-D_{r 4}-L_{4}$ are linearly decreased.

Mode 4 (Figure $8(d), t_{3} \leq t<t_{4}$ ). At time $t_{3}$, a negative voltage $V_{A B}$ will cross the resonant inductor $L_{r}$ and the primary winding of transformer $T_{r}$, since rectifier diode currents $i_{D_{r 3}}$ and $i_{D_{r 4}}$ have not been commutated completely yet. Therefore, all of the diodes $\left(D_{r 1} \sim D_{r 4}\right)$ are maintained conducting, while inductor currents $i_{L_{3}}$ and $i_{L_{4}}$ are maintained discharging to the load.

At time $t_{4}$, rectifier diode currents $i_{D_{r 3}}$ and $i_{D_{r 4}}$ have been commutated completely. Then, a positive voltage $V_{\text {sec }}$ crosses the secondary winding of transformer $T_{r}$. This ends a half switching cycle operation.

3.2. Operational Principle of CCDR. In Figure 4, each coupled inductor individually functions as a tapped inductor or a transformer during one switching cycle. In other words, the upper coupled-inductor is charged during the charging period, which functions as a tapped inductor, while the lower coupled-inductor functions as a transformer. Therefore, Figure 4 can be redrawn as shown in Figure 9. The proposed phase-shift full-bridge converter with CCDR under continuous inductor current operation can be divided into three major operating modes over a half switching cycle. Figure 10 shows conceptual voltage and current waveforms relative to key components of the converter. $D_{\text {eff }}$ and $D_{\text {loss }}$ are denoted as the effective and lost duty ratios, respectively. $V_{A B}$ is the voltage across the resonant inductor and the isolation-transformer primary winding, $V_{\text {sec }}$ is the voltage across the isolation-transformer secondary winding, $i_{\sec }$ is the secondary current, $i_{L}$ and $V_{L}$ are the current and voltage of the coupled-inductor winding $n_{1}, i_{D_{r}}$ and $V_{D_{r}}$ are the current and voltage of the rectifier diode, and $i_{o}$ is the output current. The circuit operation is explained as follows.

Mode 1 (Figure 11(a), $t_{0} \leq t<t_{1}$ ). At time $t_{0}$, currents $i_{D_{r 1}}$ and $i_{D_{r 2}}$ are commutated completely. Then, a positive voltage $V_{\text {sec }}$ crosses the secondary winding of transformer $T_{r}$; diode $D_{r 1}$ is reversely biased, and inductor current $i_{L_{1}}$ flowing through the path of $V_{o}-D_{r 2}-L_{22}-V_{\text {sec }}-L_{11}-L_{1}$ increases linearly. During this interval, the energy stored in inductor $L_{22}$ will be released to the load through coupled inductor $L_{2}$, and inductor current $i_{L_{2}}$ flowing through the path of $V_{o}-D_{r 2}$ is decreased. Meanwhile, inductors $L_{11}$ and $L_{1}$ function as 


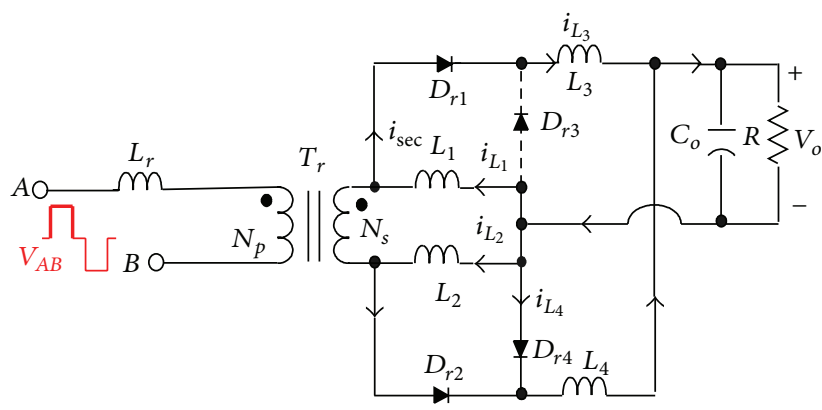

(a)

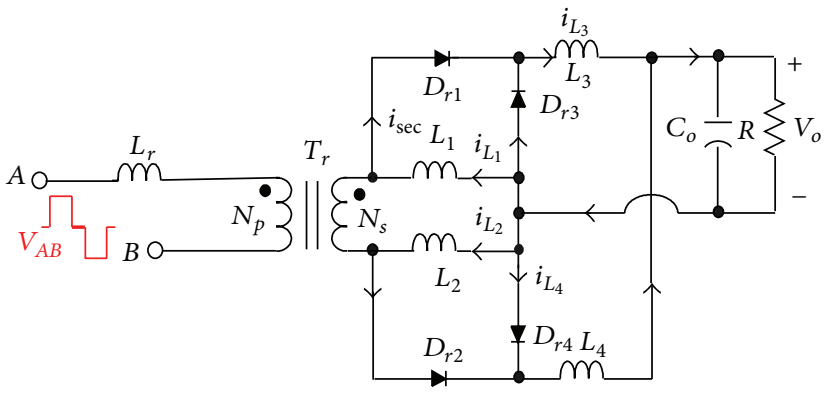

(c)

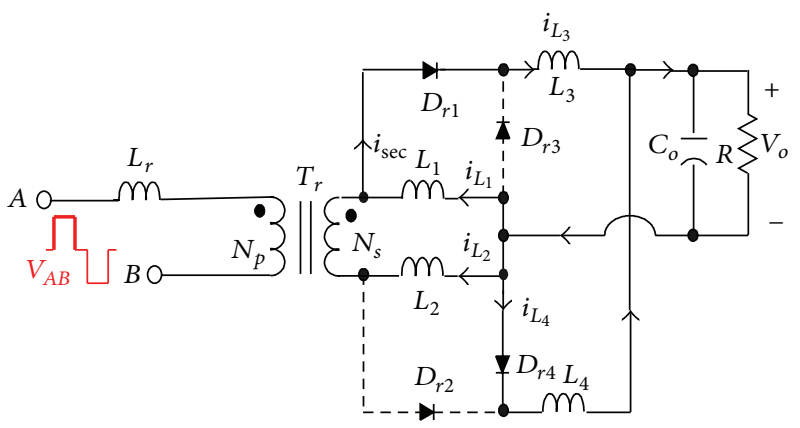

(b)

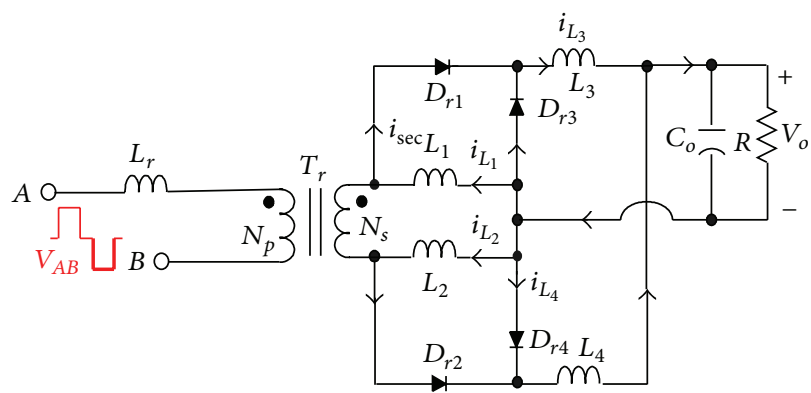

(d)

FiguRE 8: Operational modes of the proposed full-bridge phase-shift converter with NCDR: (a) mode 1, (b) mode 2, (c) mode 3, and (d) mode 4 .
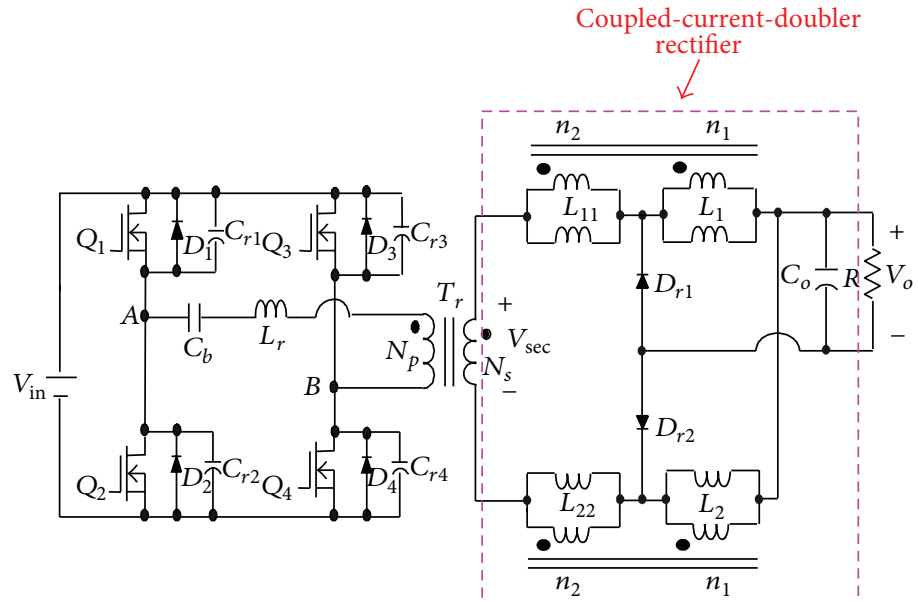

FIGURE 9: Each coupled inductor individually functions as a transformer for CCDR.

a tapped inductor, while inductors $L_{22}$ and $L_{2}$ are coupled to function as a transformer $T$.

Mode 2 (Figure 11(b), $t_{1} \leq t<t_{2}$ ). When voltage $V_{\text {sec }}$ drops to zero at time $t_{1}$, the energy stored in inductor $L_{22}$ is no longer released to the load through coupled inductor $L_{2}$. Therefore, inductor current $i_{L_{2}}$ will be gradually decreased, rectifier diodes $D_{r 1}$ and $D_{r 2}$ are conducted, and rectifier diode currents $i_{D_{r 1}}$ and $i_{D_{r 2}}$ begin commutating. During this free-wheeling interval, inductor currents $i_{L_{1}}$ and $i_{L_{2}}$ decrease linearly.

Mode 3 (Figure 11(c), $t_{2} \leq t<t_{3}$ ). At time $t_{2}$, a negative voltage $V_{A B}$ will cross resonant inductor $L_{r}$ and the primary winding of transformer $T_{r}$, since rectifier diode currents $i_{D_{r 1}}$ and $i_{D_{r 2}}$ have not been commutated completely yet. Therefore, the two rectifier diodes $D_{r 1}$ and $D_{r 2}$ are maintained conducting, while inductors $L_{1}$ and $L_{2}$ are discharged through diodes $D_{r 1}$ and $D_{r 2}$, respectively.

When currents $i_{D_{r 1}}$ and $i_{D_{r 2}}$ are commutated completely at time $t_{3}$, the converter operation over a half switching cycle is completed.

\section{Performance Comparison between NCDR and CCDR}

This section will compare both the features and characteristics of NCDR as well as CCDR, which include secondary 


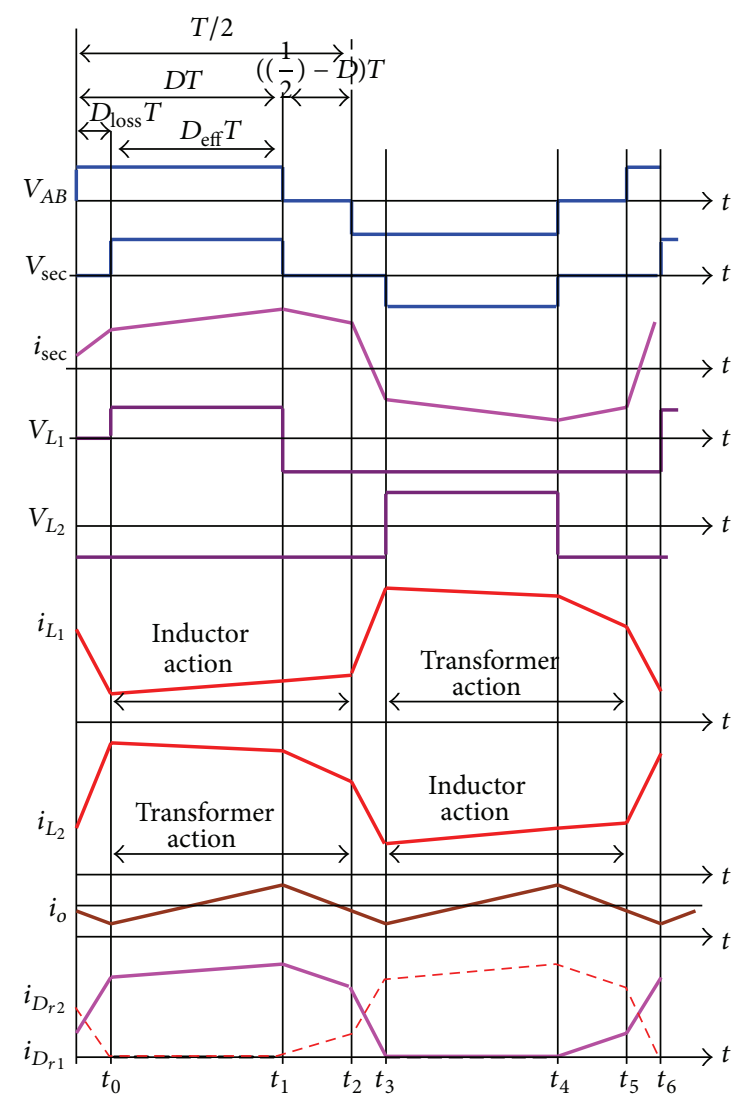

FIGURE 10: Key waveforms of phase-shift full-bridge converter with CCDR.

winding peak current of transformer, voltage gain, and output current ripple.

4.1. Performance of NCDR. From Figures 3 and 7, during one complete switching cycle, the secondary winding peak current $i_{\text {sec(peak) }}$ can be expressed as follows:

$$
i_{\text {sec(peak) }}=\frac{I_{o}}{2}+\frac{\left(V_{\mathrm{sec}}-V_{o}\right)}{8 L f_{s}},
$$

where $L=L_{1}=L_{2}=L_{3}=L_{4}, V_{\text {sec }}$ is secondary voltage of transformer, and the voltage stresses of free-wheeling diodes can be expressed as follows:

$$
\begin{aligned}
& V_{D_{r 1}}=V_{D_{r 2}}=\frac{V_{\mathrm{sec}}+V_{o}}{2}, \\
& V_{D_{r 3}}=V_{D_{r 4}}=\frac{V_{\mathrm{sec}}-V_{o}}{2},
\end{aligned}
$$

where $V_{o}$ is output voltage. By applying the volt-second balance principle to the auxiliary inductors and output filter inductors, the voltage gain of the proposed rectifier then can be derived as follows:

$$
\frac{V_{o}}{V_{\mathrm{sec}}}=\frac{D}{2}
$$

where $D$ is duty ratio of power switches. From Figure 7 again, by using the interleaved current of the output inductors $L_{3}$ and $L_{4}$, the output current ripple can be expressed:

$$
i_{o(\text { ripple })}=\frac{(1-2 D) V_{o}}{2 L f_{s}},
$$

where $f_{s}$ is switching frequency of power switches.

4.2. Performance of CCDR. From Figures 9 and 10, during one complete switching cycle, the secondary winding peak current $i_{\text {sec(peak) }}$ can be expressed as follows:

$$
i_{\text {sec (peak) }}=\left(\frac{V_{\text {sec }}-n V_{o}}{n^{2} L}\right) D T_{S}\left(\frac{n_{2}}{n_{1}}\right)-\frac{V_{o}}{L},
$$

where $L=L_{1}=L_{2}$, and the voltage stresses of free-wheeling diodes can be expressed as follows:

$$
V_{D_{r 1}}=V_{D_{r 2}}=\frac{V_{\mathrm{sec}}}{n}
$$

where $n=\left(n_{1}+n_{2}\right) / n_{1}$ is turns ratio of coupled inductors. By applying the volt-second balance principle to the auxiliary inductors and output filter inductors, the voltage gain of the proposed rectifier then can be derived as follows:

$$
\frac{V_{o}}{V_{\text {sec }}}=\frac{2 D}{n(1+n)} \text {. }
$$




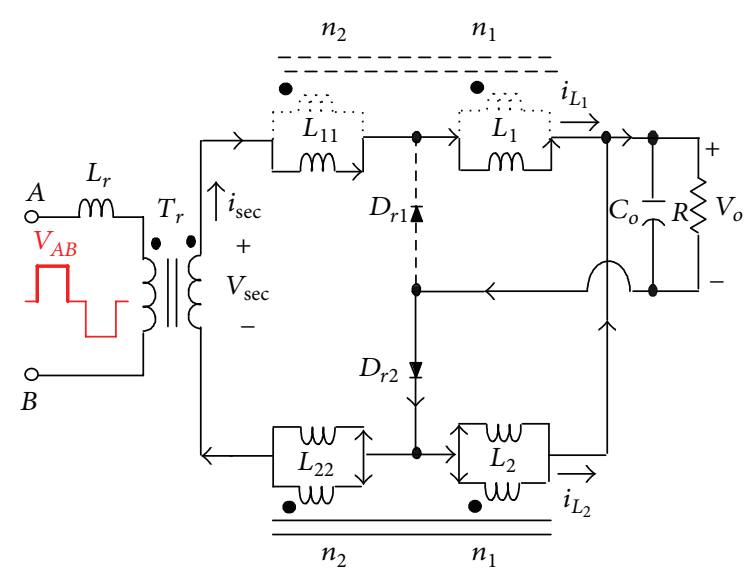

(a)

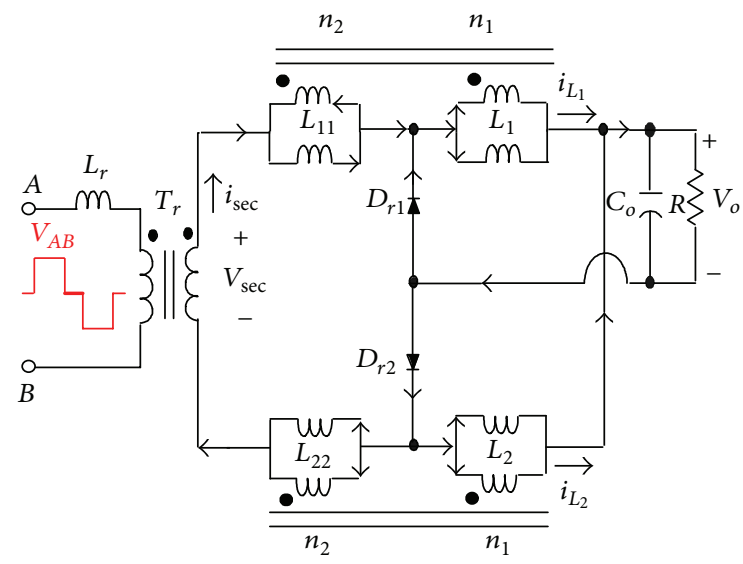

(b)

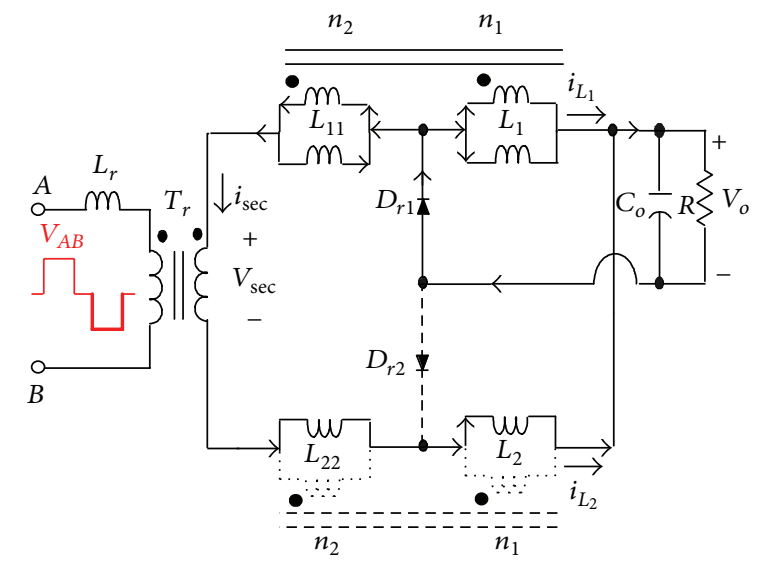

(c)

FIGURE 11: Equivalent circuit modes of the CCDR operating over a half switching cycle.

TABLE 1: Comparison between NCDR and CCDR.

\begin{tabular}{lcc}
\hline & NCDR & CCDR \\
\hline Voltage gain & $\frac{V_{o}}{V_{\text {sec }}}=\frac{D}{2}$ & $\frac{V_{o}}{V_{\text {sec }}}=\frac{2 D}{n(1+n)}$ \\
\hline Output current ripple & $i_{o(\text { ripple })}=\frac{(1-2 D) V_{o}}{2 L f_{s}}$ & $i_{o(\text { ripple })}=\left[\frac{(1+n)}{2}-2 D\right] \frac{V_{o}}{L f_{s}}$ \\
\hline Diode voltage stress & $V_{D_{r 1}}=V_{D_{r 2}}=\frac{V_{\text {sec }}+V_{o}}{2}$ & $V_{D_{r 1}}=V_{D_{r 2}}=\frac{V_{\text {sec }}}{n}$ \\
\hline $\begin{array}{l}\text { Peak current of transformer secondary } \\
\text { winding }\end{array}$ & $i_{\text {sec(peak) }}=\frac{I_{o}}{2}+\left(\frac{V_{\text {sec }}-V_{o}}{2 L}\right) D T_{s}$ & $i_{\text {sec(peak })}=\left(\frac{V_{\text {sec }}-n V_{o}}{n^{2} L}\right) D T_{S}\left(\frac{n_{2}}{n_{1}}\right)-\frac{V_{o}}{L}$ \\
\hline
\end{tabular}

From Figure 10 again, by combining the currents of $i_{L_{1}}$ and $i_{L_{2}}$, output current ripple can be determined as

$$
i_{o(\text { ripple })}=\left[\frac{(1+n)}{2}-2 D\right] \frac{V_{o}}{L f_{s}} .
$$

To objectively judge the merits and demerits of NCDR and CCDR, their performances are compared as summarized in Table 1 and Figure 12, assuming that the two improved current-doubler rectifiers can be operated with identical frequency, the same input and output voltages, and load currents.

\section{Experimental Results}

To verity the performance of NCDR and CCDR, two sets of $500 \mathrm{~W}$ prototypes with phase-shift full-bridge converters were built (see Figures 13 and 14). The specifications are listed as follows:

(i) input voltage $V_{\text {in }}: 400 \mathrm{~V}_{\mathrm{dc}}$,

(ii) output current $I_{o}: 42 \mathrm{~A}$,

(iii) output voltage $V_{o}: 12 \mathrm{~V}_{\mathrm{dc}}$. 


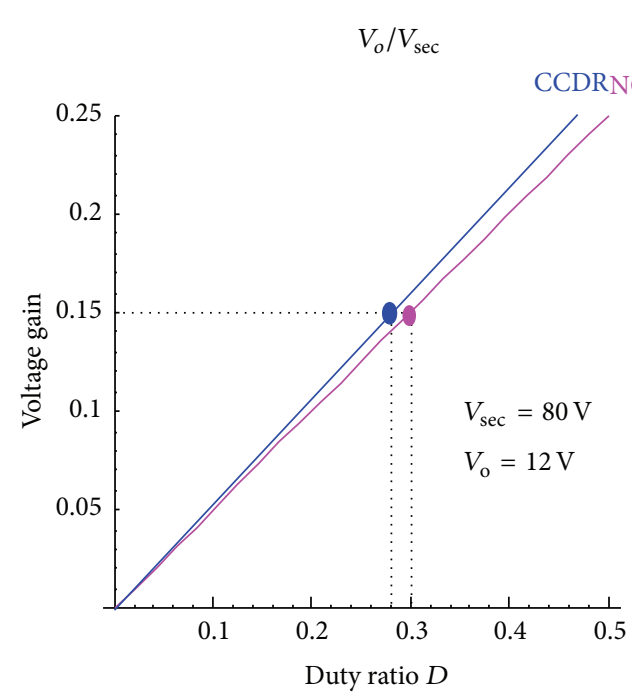

(a)

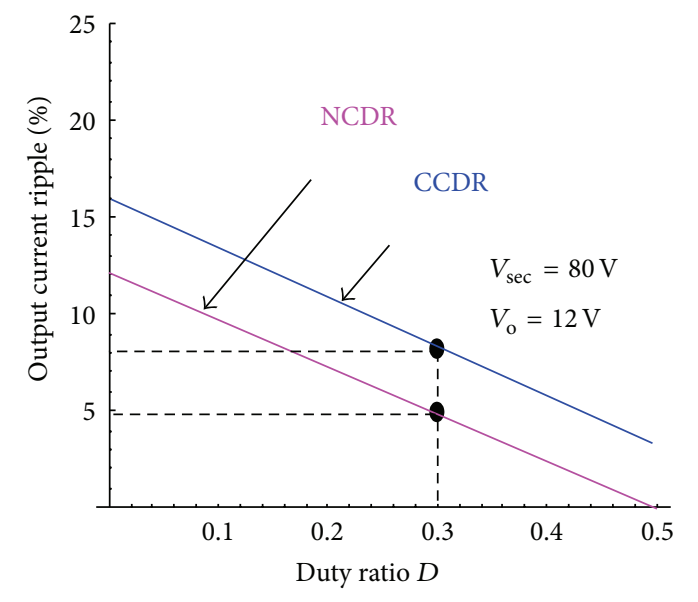

(b)

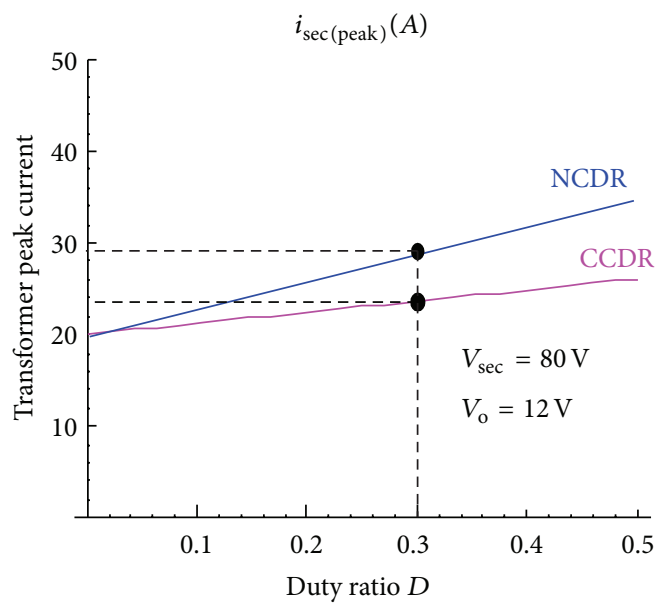

(c)

FIGURE 12: Performance comparison between NCDR and CCDR: (a) duty ratio, (b) output current ripple, and (c) secondary peak current of the transformer.

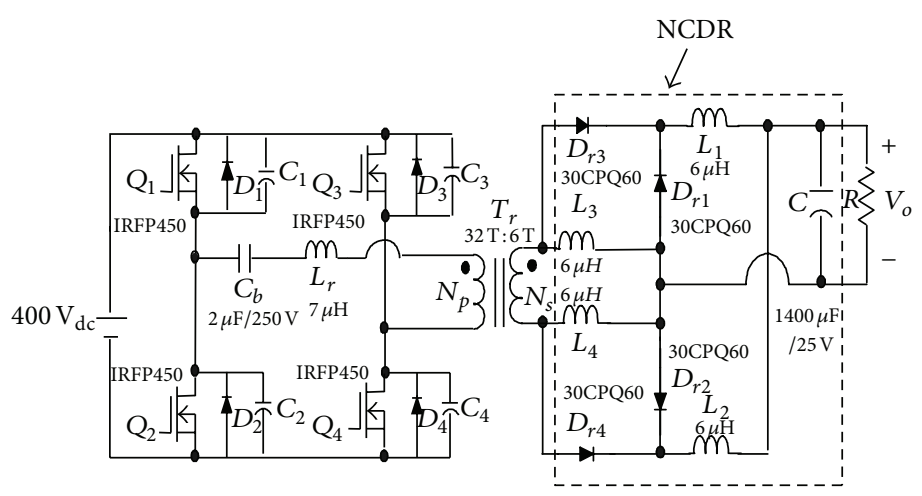

FIGURE 13: Experimental circuit of the phase-shift full-bridge converter with NCDR. 


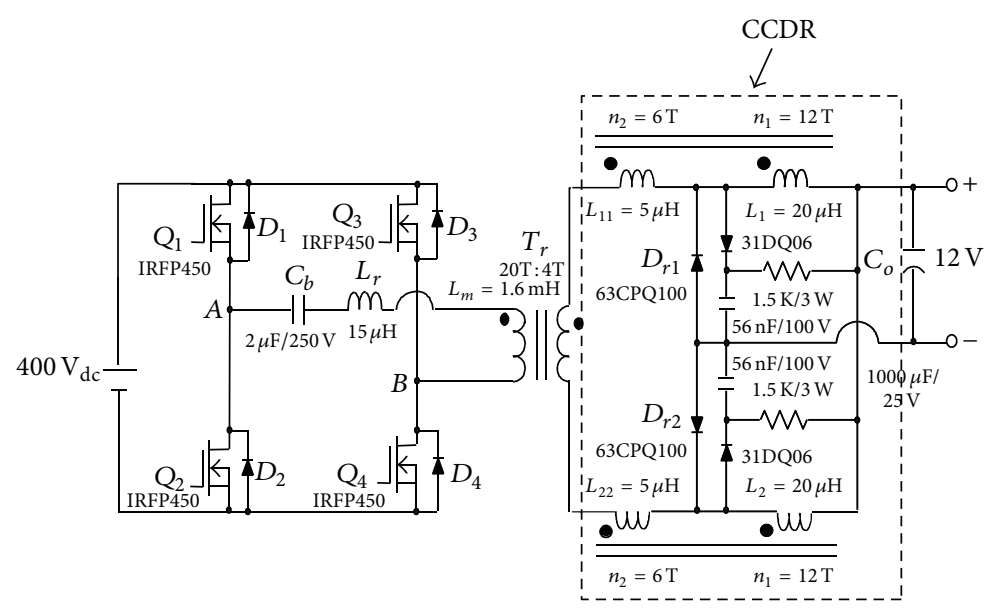

FIGURE 14: Experimental circuit of the proposed phase-shift full-bridge converter with CCDR.

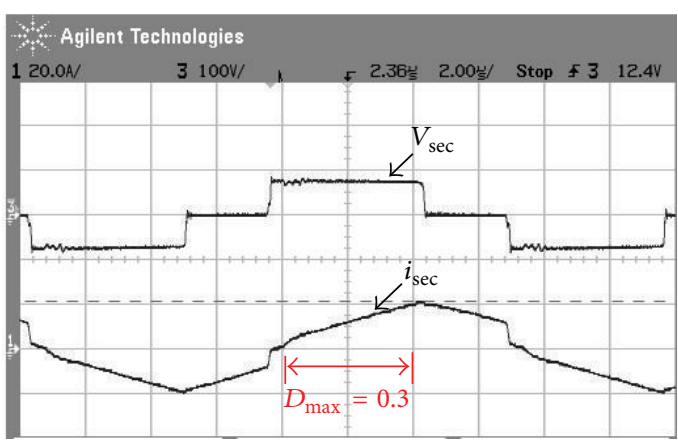

(a)

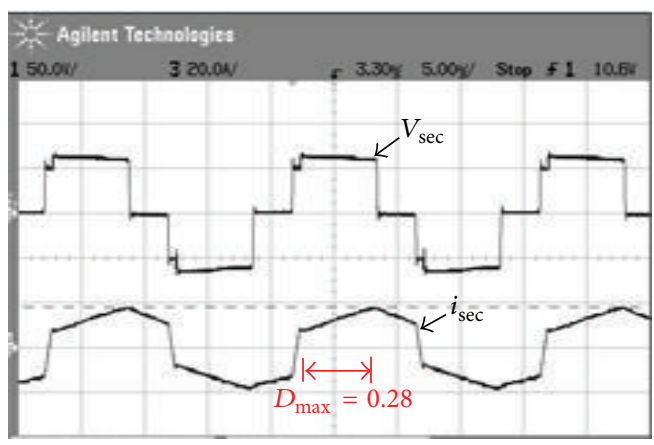

(b)

FIGURE 15: Measured waveforms of the secondary voltage and current of the transformer: (a) NCDR and (b) CCDR.

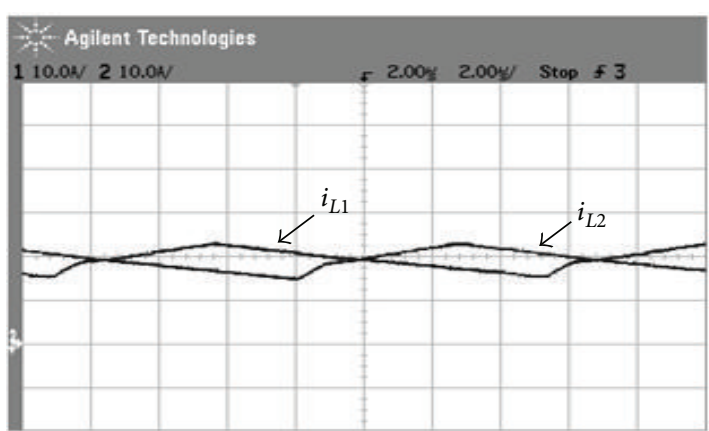

(a)

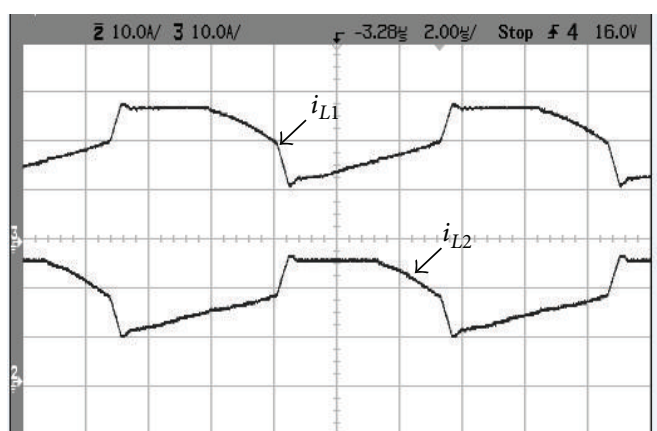

(b)

FIGURE 16: Measured waveforms of output filter inductor current $i_{L_{1}}$ and $i_{L_{2}}$ : (a) NCDR and (b) CCDR.

(iv) output power $P_{o}: 500 \mathrm{~W}$,

(v) switching frequency $f_{s}: 100 \mathrm{kHz}$.

Figure 15 shows measured transformer waveforms of NCDR and CCDR under full load condition. From these measured waveforms, it can be seen that NCDR and CCDR can be extended duty ratio. Comparing between NCDR and
CCDR, the NCDR has a wide duty ratio. Figure 16 shows waveforms of output filter inductors $L_{3}$ and $L_{4}$ for NCDR and CCDR, from which it can be seen that NCDR has lower inductor current ripple. Figure 17 shows waveforms of fullload output current, from which it can be seen that NCDR has lower output current ripple. Figure 18 shows the comparison of efficiency measurements between NCDR and CCDR, from 


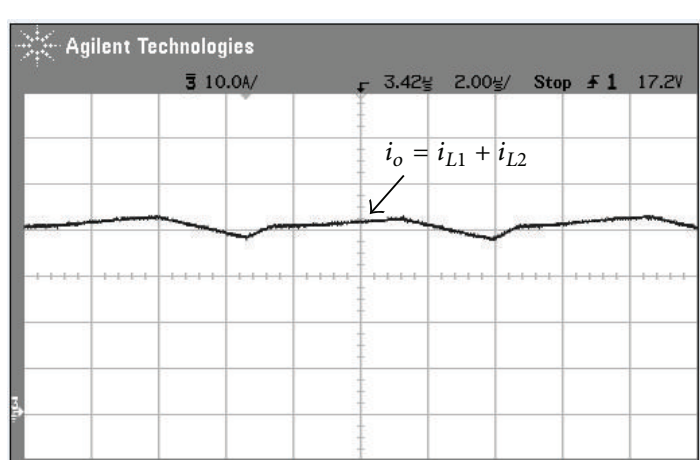

(a)

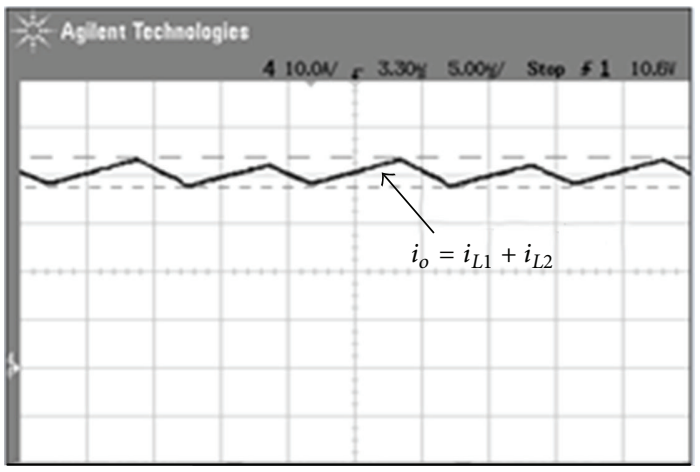

(b)

FIGURE 17: Measured output current $i_{o}$ waveforms: (a) NCDR and (b) CCDR.

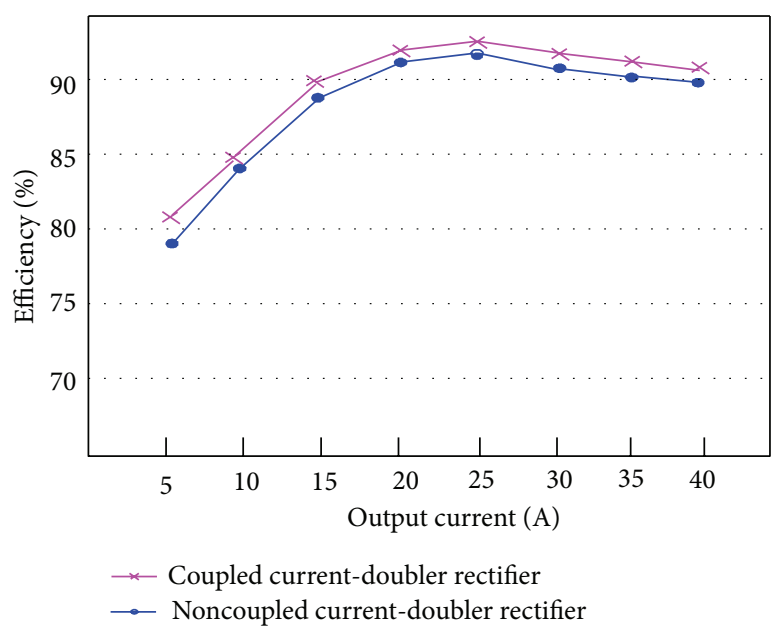

FIGURE 18: Efficiency comparison between NCDR and CCDR associated with phase-shift full-bridge converters.

which it can be seen that CCDR can achieve higher efficiency at heavy load and can reach as high as $91 \%$. The reason behind is that NCDR is used with four inductors resulting in low conversion efficiency.

\section{Conclusions}

In this paper, the proposed phase-shift full-bridge converter with NCDR and CCDR under $500 \mathrm{~W}$ has been implemented. The NCDR has the merits of extended duty ratio, lower output current ripple, and lower rectifier diodes voltage stresses, which can reduce the peak current through the isolation transformer and switches. However, in comparison between efficiency of NCDR and CCDR, the NCDR has lower efficiency at full load condition. The reason behind is that NCDR is used with four inductors resulting in low conversion efficiency. For small size and high efficiency requirements, CCDR is relatively suitable for high step-down voltage and high power conversion applications.

\section{Conflict of Interests}

The authors declare that there is no conflict of interests regarding the publication of this paper.

\section{Acknowledgment}

This work was supported by the National Science Council, Taiwan, under Grant no. NSC102-2221-E-167-024.

\section{References}

[1] N. F. Zhang and J. Xu, "A novel PCCM boost PFC converter with fast dynamic response," IEEE Transactions on Industrial Electronics, vol. 58, no. 9, pp. 4207-4216, 2011.

[2] L. Huber, Y. Jang, and M. M. Jovanović, "Performance evaluation of bridgeless PFC boost rectifiers," IEEE Transactions on Power Electronics, vol. 23, no. 3, pp. 1381-1390, 2008.

[3] J.-G. Cho, J. A. Sabaté, G. Hua, and F. C. Lee, “Zero-voltage and zero-current-switching full bridge PWM converter for highpower applications," IEEE Transactions on Power Electronics, vol. 11, no. 4, pp. 622-628, 1996.

[4] M. Xu, J. Zhou, and F. C. Lee, "A current-tripler dc/dc converter," IEEE Transactions on Power Electronics, vol. 19, no. 3, pp. 693700, 2004.

[5] Y. Jang, M. M. Jovanović, and Y.-M. Chang, "A new ZVS-PWM full-bridge converter," IEEE Transactions on Power Electronics, vol. 18, no. 5, pp. 1122-1129, 2003. 
[6] X. Ruan and Y. Yan, "An Improved phase-shifted zero-voltage and zero-current switching PWM converter applied," in Proceedings of the 13th Annual Applied Power Electronics Conference and Exposition (APEC '98), vol. 2, pp. 811-815, February 1998.

[7] J. A. Abu-Qahouq, H. Mao, and I. Batarseh, "New coupled-inductors current-doubler topology," in Proceedings of the IEEE 34th Annual Power Electronics Specialists Conference, vol. 2, pp. 648-655, June 2003.

[8] L. Y. Chang, K. H. Chao, and T. C. Chang, "Application of high voltage ratio and low ripple interleaved DC-DC converter for a fuel cell," The Scientific World Journal, vol. 2012, Article ID 896508, 11 pages, 2012.

[9] C.-T. Tsai and C.-L. Shen, "High efficiency current-doubler rectifier with low output current ripple and high step-down voltage ratio," IEEJ Transactions on Electrical and Electronic Engineering, vol. 8, no. 2, pp. 182-189, 2013.

[10] C.-T. Tsai and C.-L. Shen, "High step-down interleaved buck converter with active-clamp circuits for wind turbines," Energies, vol. 5, no. 12, pp. 5150-5170, 2012.

[11] S.-Y. Tseng and C.-T. Tsai, "Photovoltaic power system with an interleaving boost converter for battery charger applications," International Journal of Photoenergy, vol. 2012, Article ID 936843, 15 pages, 2012.

[12] C.-T. Tsai and S.-H. Chen, "PV power-generation system with a phase-shift PWM technique for high step-up voltage applications," International Journal of Photoenergy, vol. 2012, Article ID 838231, 11 pages, 2012.

[13] T.-F. Wu, C.-T. Tsai, Y.-D. Chang, and Y.-M. Chen, "Analysis and implementation of an improved current-doubler rectifier with coupled inductors," IEEE Transactions on Power Electronics, vol. 23, no. 6, pp. 2681-2693, 2008. 

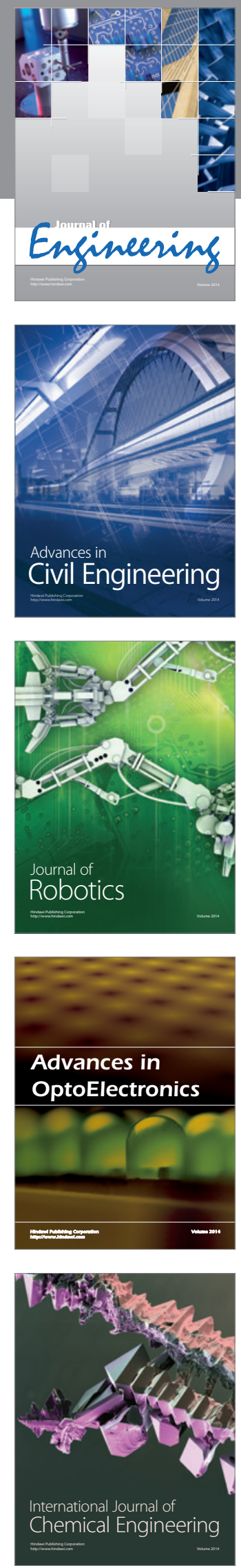

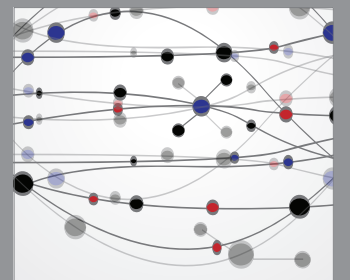

The Scientific World Journal
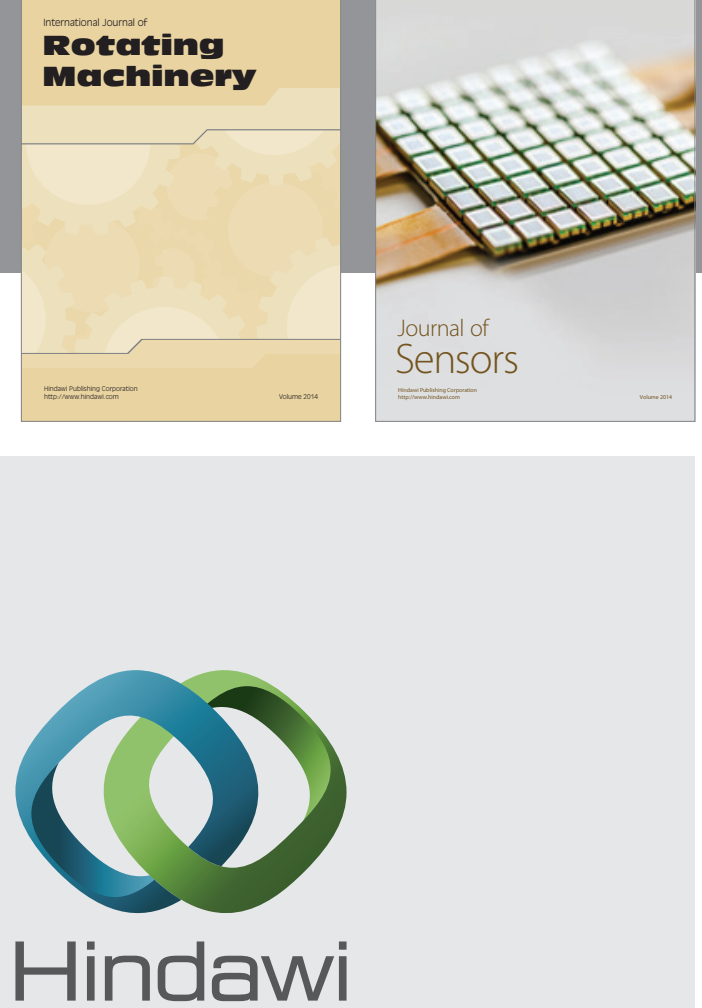

Submit your manuscripts at http://www.hindawi.com
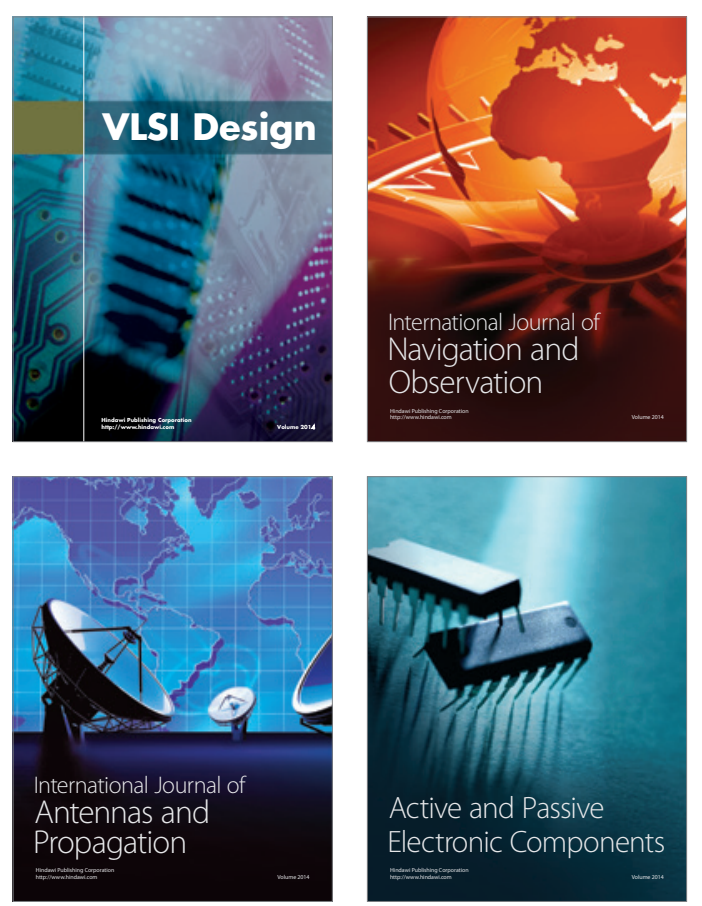
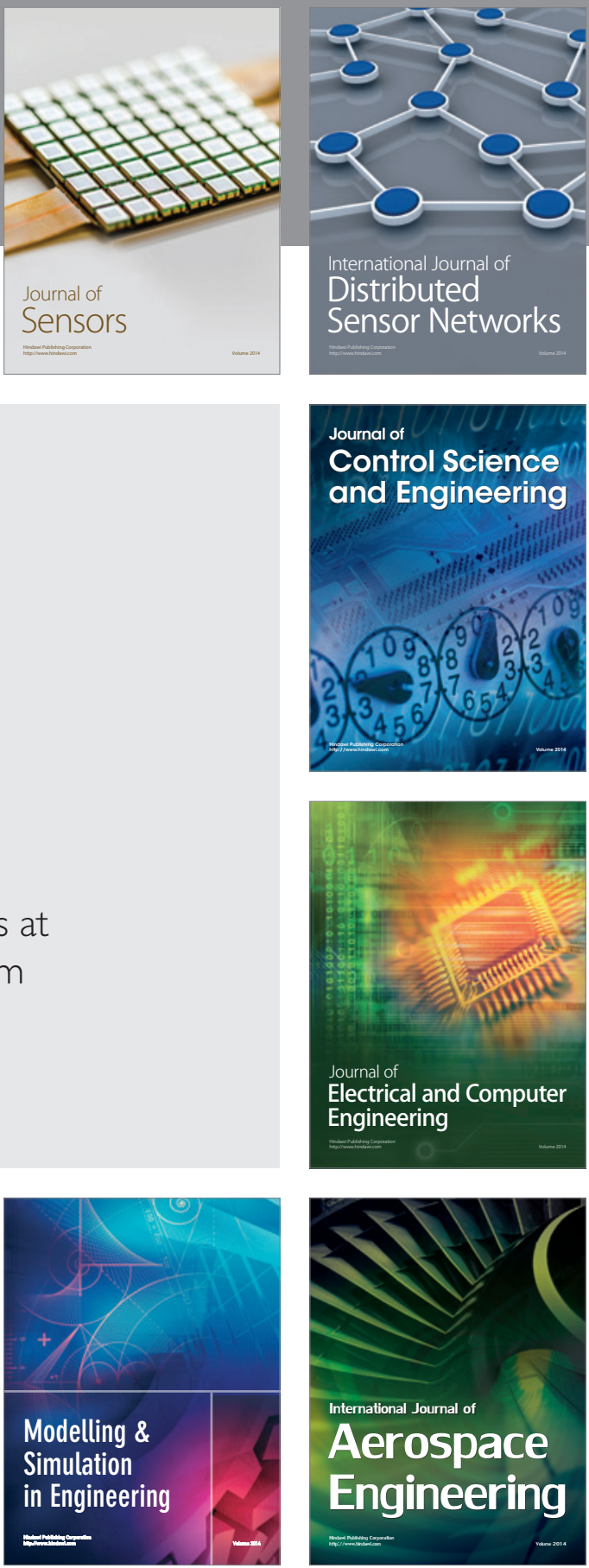

Journal of

Control Science

and Engineering
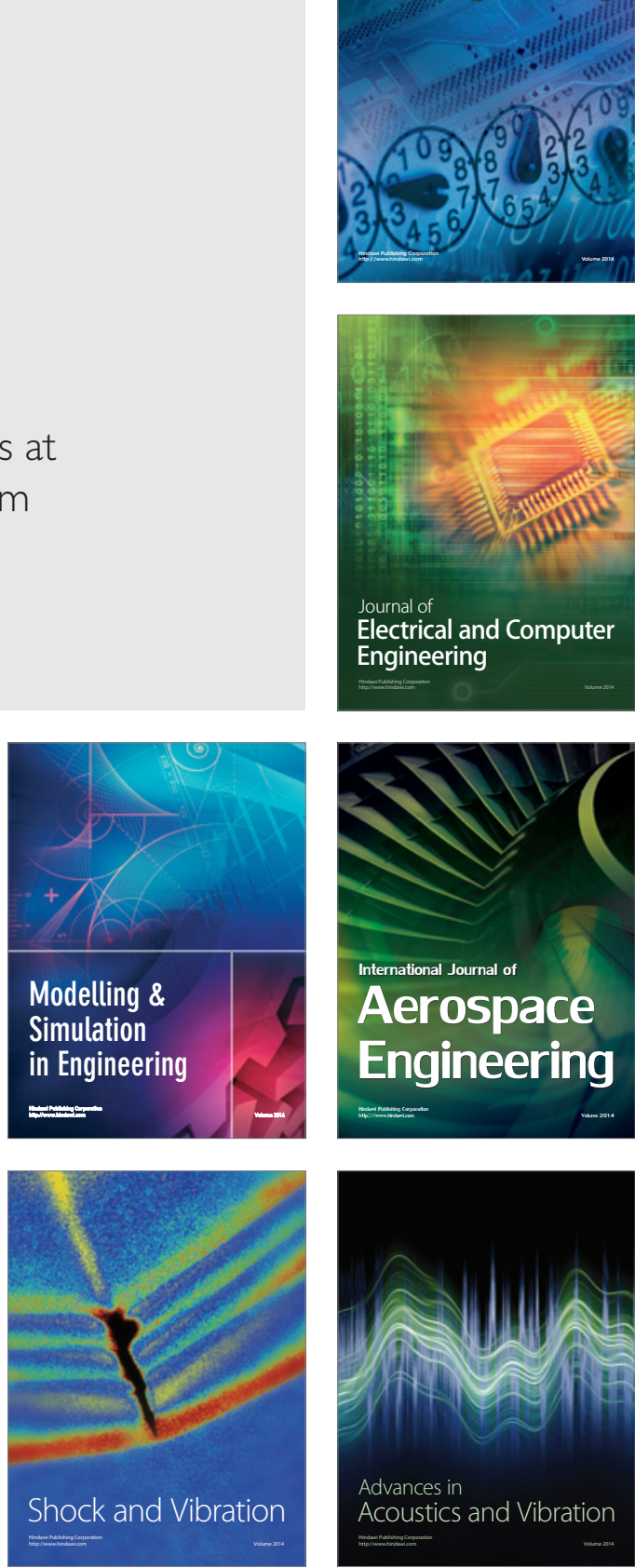